\title{
Cell Spinpods: A Simple Inexpensive Device to Determine Suspension Culture and Toxicity Effects on Renal Proximal Tubular Cells
}

Timothy G. Hammond ( $\square$ hammondoutofoffice@yahoo.com )

Cell Spinpod LLC

\section{Corey Nislow}

The University of British Columbia

Ivan C. Christov

Purdue University

Vecihi Batuman

Tulane University School of Medicine

Pranay P. Nagrani

Purdue University

Marjan Barandezeh

The University of British Columbia

\section{Rohit Upadhyay}

Tulane University School of Medicine

Guri Giaever

The University of British Columbia

Patricia L. Allen

Durham VA Health Care System

Michael Armbruster

Incept 3D

Allen Raymond

Rite Tech Industries Inc. Trinity

Holly H. Birdsall

Cell Spinpod LLC

\section{Research Article}

Keywords: suspension culture, rotating wall vessel, cell toxicity, kidney, proximal tubule, two-fluid modeling, light chains, myeloma, cytokines, next-generation sequencing 
DOl: https://doi.org/10.21203/rs.3.rs-625193/v1

License: (c) (1) This work is licensed under a Creative Commons Attribution 4.0 International License. Read Full License 


\section{Cell spinpods: a simple inexpensive device to determine suspension culture and toxicity effects on renal proximal tubular cells}

Timothy G. Hammond ${ }^{* 1,2,3,4,5}$, Corey Nislow ${ }^{6}$, Ivan C. Christov ${ }^{7}$, Vecihi Batuman ${ }^{4}$, Pranay P. Nagrani ${ }^{7}$, Marjan Barandezeh ${ }^{6}$, Rohit Upadhyay ${ }^{4}$, Guri Giaever ${ }^{6}$, Patricia L. Allen ${ }^{1}$, Michael Armbruster ${ }^{8}$, Allen Raymond ${ }^{9}$, and Holly H. Birdsall ${ }^{*, 3,4,5,10,11}$

1 Nephrology Section, Medicine Service Line, Durham VA Health Care System, Durham, NC 27705, USA

2 Nephrology Division, Department of Internal Medicine, Duke University School of Medicine, Durham, NC 27705, USA

3 Space Policy Institute, Elliott School of International Affairs, George Washington University, Washington, DC, 20052, USA

4 Nephrology Section, John W. Deming Department of Medicine, Tulane University School of Medicine, New Orleans LA 70112, USA

5 Cell Spinpod LLC, Chapel Hill, NC 27516, USA

6 Faculty of Pharmaceutical Sciences, The University of British Columbia, Vancouver, British Columbia, V6T 1Z3, Canada

7 School of Mechanical Engineering, Purdue University, West Lafayette, IN 47907, USA

8 Incept 3D, San Diego CA 92121, USA

9 Rite Tech Industries Inc. Trinity, FL 34655, USA

10 Departments of Otorhinolaryngology, Immunology, and Psychiatry, Baylor College of Medicine, Houston, TX 77030, USA

11 Otolaryngology Section, Surgery Service Line, Durham VA Health Care System, Durham, NC 27705, USA

Correspondence should be addressed to:

Timothy Hammond M.B., B.S.

Durham VA Health Care System

Building 15, Room 210

508 Fulton Street

Durham NC 27705 USA

Telephone: (919)-428-5055

FAX: (919)-323-8644

E-mail: hammondoutofoffice@yahoo.com

Running Title: Cell spinpod form of rotational culture enhances suspension culture effects of toxins on renal cells.

${ }^{*}$ Correspondence:

Timothy Hammond M.B., B.S.

hammondoutofoffice@yahoo.com

Keywords: suspension culture, rotating wall vessel, cell toxicity, kidney, proximal tubule, two-fluid modeling, light chains, myeloma, cytokines, next-generation sequencing. 


\section{Abstract}

Rotating forms of suspension culture allow cells to aggregate into spheroids, prevent the de-differentiating influence of adherence to plastic surfaces, and, perhaps most importantly of all, provide physiologically relevant, in vivo levels of shear stress. Suspension culture technology has not, however, been widely implemented, in large part because the vessels are prohibitively expensive, labor-intensive to use, and are difficult to scale for industrial applications. Our solution addresses each of these challenges in a new vessel called a cell spinpod. These small $3.5 \mathrm{~mL}$ capacity vessels are constructed from injection molded thermoplastic polymer components. They contain self-sealing axial silicone rubber ports, and fluoropolymer, breathable membranes. Here we report the development of injection molded cell spinpods with two-fluid modeling of the flow and stresses. Their validation was accomplished using immortalized human renal proximal tubular cells for functional assays, renal damage marker release, and differential gene expression analysis via next-generation sequencing. During exposure to myeloma immunoglobulin light chains, rotation increased both toxin-induced cell death, and release of clinically validated nephrotoxicity cytokine markers in a toxinspecific pattern. Cell spinpods are a sensitive tool for detecting nephrotoxicity in vitro. 


\section{Introduction}

Cells in the body are exposed to flow shear stress as fluids, such as blood or renal glomerular filtrate, stream past the cell's membranes [1, 2]. For example, in the kidney, fluid from the blood is filtered by the glomerulus, and this ultrafiltrate pours past proximal tubule cells (PTC) that are responsible for reabsorbing water, sodium, glucose, amino acids, and diverse hormones and proteins. This is not a languid process - a healthy kidney generates over $100 \mathrm{~mL}$ of ultrafiltrate per minute and the PTC are responsible for reabsorbing $70 \%$ of this volume. During these processes, cells of the proximal tubule experience profound shear stress. Calculations of the actual fluid shear stress in vivo is complicated by the varying dimensions of the tubules and varying composition of the ultrafiltrate as it moves down the tubule, but it is estimated that PTC are exposed to shear stress in the range of $0.04-2$ dynes $/ \mathrm{cm}^{2}[1,3-5]$.

This fluid shear stress has an important role in maintaining the differentiation of PTC $[2,6]$. Exposure to fluid shear stress in vitro increases PTC transport of proteins [7-12], expression of microvilli [10], and formation of tight junctions, with increased transepithelial electrical resistance [13-19]. Accordingly, in order to serve as meaningful and representative models of living kidneys, cultured PTC in vitro must be exposed to fluid shear stress in a quantifiable manner $[2,20]$.

Generating fluid shear stress in vitro presents a variety of challenges (reviewed in [2]). Several technologies are available including orbital shakers, parallel plates, microfluidics with peristaltic pumps, and perfused hollow fibers [8, 13, 21-24]. But most of these options require expensive equipment and are rarely practical for high throughput analysis due to high cost and/or large vessel volumes [2]. Roller bottles, paddle stirrers, and shakers are inexpensive options that are quite suitable for microorganisms with rigid cell walls such as fungi, bacteria, and algae that can tolerate high shear levels induced by turbulent flow and are relatively resistant to injury from impact against the vessel walls and paddles. In contrast, mammalian cells require much gentler treatment to avoid cellular damage and to accurately mimic the shear levels they experience in vivo $[5,25]$.

Rotating suspension cultures, where cells float in a liquid milieu, have significant advantages for delivering physiologic levels of flow shear stress. Suspension culture technology has been modeled, validated experimentally, and partially standardized for routine use $[6,26,27]$. In these cases, controlled shear is achieved by zero headspace, in which the vessel is entirely filled with culture media so that the contents rotate in laminar flow and avoid turbulent flow entirely $[1,28]$. The rotating wall vessel spins around a horizontal axis and the cells move in an annulus around the axis of rotation. Cells and aggregates of different sizes and densities co-localize in the annulus. Cells do not need to adhere to a plastic surface and thereby avoid the de-differentiation associated with 2D cultures. However, adherent cells can also be grown in rotating vessels after attachment to microcarrier beads or other scaffolds. Gas permeable membranes allows for gas exchange. 
Despite its advantages, rotating suspension culture has found limited application due to limitations of the currently available hardware [2]. For example, re-usable vessels have multiple components, each requiring sterilization by autoclaving at different temperatures, as well as complex manual assembly in a sterile environment. During use, the vessels attach to spindle rotators that spin with great precision. However, the rotators are relatively expensive and they only accommodate a few vessels at one time, constraining the design of experiments in which large numbers of replicates are desirable [2]. In the most common applications, rotating suspension cultures are used to generate a large batch of tissue spheroids that are then transferred to other (static) systems for experimentation. In this case the advantages of suspension culture are lost.

There is a compelling need for small, affordable, simple-to-use suspension culture devices for studies with large numbers of replicates $[2,6]$. We report the development and utility of an inexpensive, simple to use, rotating suspension culture device, called a cell spinpod. Our injection-molded cell spinpods are validated here by two-fluid modeling of flow and stresses, functional studies, and differential gene expression analysis via next-generation sequencing of mRNA. These studies on immortalized renal proximal tubular cells rotated and static, with and without nephrotoxin exposure, illustrate that cell spinpods provide a sensitive nephrotoxicity assay in vitro.

\section{Materials and Methods}

\section{Cell spinpods}

Cell spinpods are injection-molded polystyrene cylinders with a $3.5 \mathrm{~mL}$ capacity (Figure 1). Two self-sealing silicone ports embedded in the rotating rim allow sample loading/removal from one port with simultaneous air bleeding from the other port (Figure 1 , panel a). The cell chamber is sandwiched between two translucent Fluoropolymer membranes that retain water aggressively but freely exchange oxygen and carbon dioxide (Figure 1, panel a). The cell spinpods are rotated on a laboratory bottle roller (Thermo-Fisher, Waltham MA) in a $5 \% \mathrm{CO}_{2}$ incubator (Figure 2, panel b).

\section{Cells}

Frozen aliquots of RPTEC/TERT1 cells (ATCC CRL-4031, Manassas, VA) [29] were thawed and expanded as monolayer cultures in DMEM/F12, supplemented with 'SingleQuots' containing cell-type specific growth supplements (Lonza, Morrisville, NC) $[10,30]$. Cells were cultivated in a $37^{\circ} \mathrm{C}$ incubator with a $5 \% \mathrm{CO}_{2}$ humidified atmosphere and passaged when $70 \%$ confluent. Immediately before loading the cells into cell spinpods, trypsinized RPTEC/TERT1 at $0.5 \times 10^{6} \mathrm{cells} / \mathrm{mL}$ were allowed to attach to a suspension of preswollen Cytodex- 3 collagen microcarrier beads $(25 \mathrm{mg} / \mathrm{ml}$, average diameter $175 \mu \mathrm{m}$; Sigma-Aldrich, St. Louis, MO) for one hour at $37^{\circ} \mathrm{C}$. The cell/bead mixture was adjusted to a final concentration of $5 \times 10^{4} \mathrm{cell} / \mathrm{mL}$ with 2.5 $\mathrm{mg} / \mathrm{mL}$ beads for loading into the cell spinpod [10, 30].

\section{Cell spinpod loading and harvest}


$3.5 \mathrm{~mL}$ of RPTEC/TERT1 on Cytodex-3 beads, representing approximately 1.75 $x 10^{5}$ total cells, were inoculated into each cell spinpod by gravity flow using a $5-\mathrm{mL}$ syringe and 18-gauge needle. A second 27-gauge needle was inserted in the second port allowed the escape of air during loading (Figure 2, panel a).

The cell spinpods were rotated at 30 revolutions per minute on a bottle roller in a $5 \% \mathrm{CO}_{2}$ incubator (Figure 2, panel b). The Bonn criteria are a standardized template for defining the conditions of rotating suspension cultures [31]. For cell spinpods in our experiments, the Bonn criteria are as follows: cell chamber diameter of $1.9 \mathrm{~cm}$, rotation speed of $30 \mathrm{rpm}$, media viscosity of 0.78 centipoise, media density of $1 \mathrm{~g} / \mathrm{mL}$, cell diameter of 12 microns, cell density of $1.05-1.07 \mathrm{~g} / \mathrm{cm}^{3} ; 175$ micron spherical Cytodex-3 beads with a density of $1.04 \mathrm{~g} / \mathrm{cm}^{3}$ and zero porosity.

Cell spinpods were rotated continuously for 0 to 72 hours, as noted in individual experiments. As controls, static cell spinpods were laid flat and maintained stationary in the $\mathrm{CO}_{2}$ incubator for the same period of time. At the end of the experiment, the cells and media were harvested by incising the membrane with a scalpel blade. For gene expression pathway analyses, the cell pellet was snap frozen in liquid nitrogen prior to library preparation for next generation sequencing and analysis by Gene Set Enrichment Analysis (GSEA) and Cytoscape visualization. For flow cytometry studies, the cell/bead pellet was washed once with $3 \mathrm{~mL}$ of phosphate buffered saline and incubated with 200 microL trypsin/EDTA for 60 seconds at $37^{\circ} \mathrm{C}$ to detach the cells from the beads. Trypsinization was stopped with the addition of $100 \mathrm{~mL}$ fetal bovine serum, and the cells were again washed with $3 \mathrm{~mL}$ of phosphate buffered saline.

\section{Flow Cytometric analysis of viability and apoptosis}

For viability analyses, the cell pellet was resuspended in Annexin-binding buffer (Life Technologies, Carlsbad CA) and filtered through 70 micron Flowmi® Cell Strainers (Millipore Sigma, St. Louis MO) to remove beads. $100 \mu \mathrm{L}$ of cells were stained with 5 $\mu \mathrm{L}$ Annexin V, Alexa Fluor 488 conjugate per manufacturer's instructions (Life Technologies, Carlsbad CA) and $1 \mu \mathrm{L}$ of $1 \mathrm{mg} / \mathrm{mL}$ propidium iodide (PI). Cells were analyzed on a Beckton-Dickenson Accuri C+ flow cytometer using log amplified photomultipliers. With every run, quality control was performed on the instrument with 3 color fluorescent beads, followed by assay of four control tubes: no dyes, annexinV alone (488nm excitation 533/30nm emission), PI alone (488nm excitation 585/40nm emission), and annexinV plus PI together to set compensation. 2000 events were recorded from each sample and all flow cytometry values are in arbitrary fluorescence units.

\section{Cytokines and renal damage markers}

Supernatants of the cells cultured in cell spinpods were assayed for Neutrophil Gelatinase-Associated (NGAL or Lipocalin-2) and plasminogen-activator inhibitor (PIA), as indicators of renal cell damage, and for thirteen cytokines/chemokines (IL-1, IL-2, IL4, IL-5, IL-6, IL-8, IL-10, IL-12, IL-13, GM-CSF, IFN $\gamma$, MCP-1, and TNF $\alpha$ ) using Luminex 
XMAP technology for multiplexed analyses by Eve Technologies Corp. (Calgary, Alberta, Canada).

\section{Uptake of FITC albumin and FITC dextran}

RPTEC/TERT1 cells on Cytodex carrier beads were cultured in cell spinpods under rotating or static conditions for 48 hours before addition of 4000 MW FITCDextran (1 $\mathrm{mg} / \mathrm{mL})$ [11] or FITC-albumin $(400 \mu \mathrm{g} / \mathrm{mL})$ [12, 32]. For cell spinpods receiving FITC-albumin, $3 \mathrm{~mL}$ of the initial complete media, containing $0.5 \%$ fetal bovine serum, was removed and replaced with $3 \mathrm{~mL}$ of serum-free media. The final media contained $400 \mu \mathrm{g} / \mathrm{mL}$ of FITC-albumin and $20 \mu \mathrm{g} / \mathrm{mL}$ of unlabeled albumin. Control cell spinpods contained complete media alone. Cell spinpods were returned to rotation or static conditions for an additional 24 hours before the cells were harvested, trypsinized off the carrier beads, as described above, and analyzed by flow cytometry. Preliminary experiments were conducted with RPTEC/TERT1 cultured in 12-well plates to validate uptake of the dextran and albumin and optimize the incubation time. After incubation with the FITC-labeled substrates, wells were washed twice with phosphate buffered saline, the cells were gently trypsinized off the plate, washed again, and passed through a $70 \mu \mathrm{M}$ mesh to remove aggregates before analysis by flow cytometry. Extending the incubation time from 2 hours to overnight resulted in an eight-fold increase in uptake (data not shown). As a validation of specificity, uptake of FITC albumin uptake was $84 \%$ competitively inhibited by the addition of an 80 -fold excess of unlabeled albumin (data not shown).

\section{Gene Set Enrichment (GSEA) Analysis}

Triplicate rotating and static cell spinpods with RPTEC/TERT1 cells on Cytodex carrier beads were harvested after $0,3,24$, and 72 hours and each cell pellet was snap frozen for GSEA analysis. Total RNA was extracted using the Qiagen (Hilden, Germany) RNA easy protocol, followed by genomic DNA removal using Ambion turbo DNase columns (Thermo-Fisher). RNA-SEQ libraries were prepared using the MGIEasy RNA library prep set (Complete Genomics Inc. San Jose CA) procedure and a minimum of 20 million reads were collected/sample on an MGI-200 sequencer using the 2X100 paired-end protocol. Reads were mapped using tophat2 and the transcripts were quantified using cufflinks. Differential expression (DE) analysis was performed using cuffdiff, and differentially expressed genes were determined using first a cut-off of FDR $<0.05$ and then a $>2$-fold change. GSEA v.4.0.0 was used to perform the Gene Set Enrichment Analysis [33] (Broad Institute, Cambridge, MA) using both all DE genes together and upregulated and downregulated genes separately. The enrichment maps were visualized in Cytoscape [34, 35].

\section{Myeloma free light chains}

Myeloma free light chains were purified from the urine of patients who had multiple myeloma, light chain proteinuria, and clinical evidence of significant renal damage that was presumed to be cast nephropathy, using ammonium sulfate precipitation and Sephadex chromatography as described previously [36]. The purity and identity of the light chains were confirmed by SDS-PAGE and Western blotting and all specimens were determined to be endotoxin-free by Liumulus ameboecyte assay. 
Light chains were stored in lyophilized form until dissolved in tissue culture media and sterile-filtered before addition to cells. Light chains from six donors were evaluated, in serial dilutions, for their toxic effects on RPTEC/TERT1 cells, in static adherent cultures using 96-well plate format. Two donors' light chains were selected for the present studies. At a dose of $100 \mu \mathrm{M}$, light chain B caused a $66 \%$ reduction in the proliferation of renal cells whereas light chain $\mathrm{C}$ only reduced cell numbers by $5 \%$ reduction (data not shown). The isolation and use of the light chains was approved by the IRB at the Tulane Office of Human Research Protection (IRB reference no. 848169). The experiments were performed in accordance with relevant guidelines and regulations, informed consent was obtained from all participants and/or their legal guardians, and all protected health information was deidentified.

\section{Statistical analyses}

Error bars in figures are the mean \pm standard error of the mean for the indicated number of replicates. Significance was determined using two-tailed Student's t-test.

\section{RESULTS}

\section{Cell Spinpods}

The cell spinpod design was created using 3D modeling software. Stereolithography (SLA) 3D printing was used for development of prototypes for multiple CAD configurations. Each configuration was tested and modified until an optimal sealing condition was obtained, based on empirical testing. Once finalized, the parts were produced by injection molding, assembled, and radiation-sterilized as single-use, disposable, vessels for rotating suspension culture.

The cell spinpod is a polystyrene cylinder with a $3.5 \mathrm{~mL}$ capacity (Figure 1). Two self-sealing silicone ports are embedded in the rotating rim to allow sample loading/removal from one port with simultaneous air bleeding from the other port (Figure 1, panel a) (video 2 in Supplemental data). The cell chamber is sandwiched between two translucent Fluoropolymer membranes that retain water aggressively but freely exchange oxygen and carbon dioxide. Gas-exchange was documented as a $\mathrm{pH}$ change, i.e. through the change from a characteristic salmon-color of phenol redcontaining media in $5 \% \mathrm{CO}_{2}$ atmosphere to the more purple color in room air. The adequacy of gas exchange was further validated by the ability of the cell spinpods to support the growth of cells, as shown below. In our tests, over three hundred cell spinpods have been filled with media and cultured for three or more days without any evidence of contamination or leakage.

The cell spinpods are rotated on a laboratory bottle roller in a $5 \% \mathrm{CO}_{2}$ incubator (Figure 2, panel b). A standard laboratory bottle roller can hold at least 40 cell spinpods. As it rotates, the cell spinpod provides continuous sedimentation of particles through culture medium while rotating as a solid mass in laminar flow with regulatable, physiologic levels of induced cellular shear and with no turbulence, as detailed below [5, 20, 37-39] (see video 1 in supplementary data). 
Because the breathable membranes are also optically clear, the contents of the cell spinpod can be monitored in situ by microscopy, without removal of the sample from the culture vessel (Figure 2, panel c). This allows continual monitoring over the course of several days. At the conclusion of the experiment, the cells can be harvested by incising the membrane with a scalpel blade (Figure 2, panel $\mathbf{d}$ ), or by aspiration with a needle through the silicone port.

\section{Laminar flow and fluid shear stress inside the cell spinpod}

In a rotating suspension culture with no headspace (i.e. when the chamber is completely full of media), the cells and medium rotate as a cohesive mass in laminar flow with no turbulence [1]. As the cells tend to sediment under the influence of gravity, the rotation of the vessel, brings them back up into suspension. Particles (e.g. cells or spheroids) sediment through the fluid until they reach terminal velocity in which the accelerated motion induced by gravity is balanced by the viscous drag of the medium [1]. Terminal velocity (Vs) is defined by:

$$
\text { Terminal Velocity }=\mathrm{Vs}=\frac{2 g r^{2}(\rho \mathrm{p}-\rho \mathrm{f})}{9 \mu}
$$

where Vs is directly dependent on $g$ (Earth gravity), the square of the radius of the particle $(r)$, and the difference between the density of the particle $(\rho p)$ and the density of the suspension fluid $(\rho f)$. Vs is inversely dependent on the viscosity of the suspension medium $(\mu)$ [1]. Maximum shear stress on the particle is a function of the terminal velocity, viscosity of the medium. and the diameter of the particle as defined by:

$$
\text { Maximum Shear Stress }=\operatorname{tmax}=\frac{3 \mu \mathrm{Vs}}{2 r}
$$

In a rotating suspension cuture with zero headspace, cells are exposed to $\sim 0.4$ to 0.12 dynes $/ \mathrm{cm}^{2}$ of shear stress [1, 6, 37, 40-42]. It is important to note that, in the equations above, the rotation speed does not affect shear stress, but rather determines the diameter of the annulus through which the cells migrate. Hence, rotating suspension culture delivers the same shear on the same size and density cells in the same media every time regardless of rotation speed. This gives the investigator broad parameters for rotation speed and makes delivering shear stress reproducibly facile.

The fluid mechanical forces experienced by cells in the cell spinpod were simulated based on the two-fluid-model recently proposed by Municchi et al [43]. Verified simulations were performed matching the specifications of the cell cultures and cell spinpods as described above. Municchi et al have recently proposed a new computational simulation approach based on the two-fluid model (TFM), in which both the particle and fluid phases of a suspension are considered as interpenetrating continua with their own conservation of mass and momentum equations [43]. The TFM is able to accurately predict particle migration and the non-uniform distribution of suspension stresses. Unlike simpler diffusive flux models used in the literature to model flow and stresses in RWVs [44], the TFM does not require the assumptions of a steady suspension velocity and a Stokesian (inertia-less) fluid. Furthermore, the TFM formulation of Municchi employs suitable anisotropic rheological models to enable 
simulation of suspension dynamics in general unsteady curvilinear flows, such as those encountered inside RWVs [43]. The TFM is implemented using the OpenFOAM® opensource C++ platform (www.openfoam.org) [45].

Figure 3, shows the calculated distribution of particles and the fluid shear stress they encounter in a cell spinpod once steady state laminar flow has been achieved (about 500 seconds after the onset of rotation. Cells are not uniformly distributed throughout the chamber but rather tend to travel in an annular path. Figure 3 panel a shows the volume fraction of particles and velocity vectors illustrating the suspension flow and the distribution of the magnitude of the deviatoric stress tensor of the particle phase The plots shown are in a cross-section perpendicular to the rotation axis, having first achieved a steady state in the simulation upon starting the rotation from rest. Figure 3 panel $\mathbf{b}$ shows the shear stress on the particles. The highest stresses on the particle phase are encountered near the vessel wall (strongest shear) but rapidly decrease to a level of about 0.5 dynes $/ \mathrm{cm}^{2}$ in the annular region slightly inward from the wall, wherein the volume fraction of particles is highest $(\approx 30 \%)$.

\section{Cell viability and apoptosis in cell spinpods}

Flow cytometry was used to measure uptake of annexinV and propidium iodide to identify and quantify apoptotic and dead cells (Figure 4, panel a). After three days of culture, there were more viable cells, and fewer apoptotic cells in rotating cell spinpods compared to static cell spinpods (Figure 4, panel b), but the magnitude of the difference did not reach statistical significance. The improved viability of renal cells exposed to fluid shear stress in rotating suspension cultures was also demonstrated by measuring the quantity of renal cell damage markers released. RPTEC/TERT1 cells cultured in rotating cell spinpods released significantly $(p=0.0000004)$ lower quantities of neutrophil gelatinase-associated lipocalin (NGAL), a documented marker of renal cell injury in vitro and in vivo [46-50]. NGAL levels in rotating renal cell cultures were $76 \pm 3 \%$ of the NGAL levels in static cultures (mean \pm SEM of 28 replicates pooled from five experiments, data not shown). The quantities of Plasminogen Activator Inhibitor-1 (PAI1) released by the same cultures did not differ between rotation and static spinpods $(p=0.48$; data not shown).

\section{Uptake of FITC albumin and FITC dextran}

The functionality of renal cells exposed to fluid shear stress in rotating suspension cultures was also demonstrated by their increased ability to take up albumin and dextran (Figure 5). Rotation in a cell spinpod doubled the uptake of FITC-albumin $(p=0.006)$ and 4000 MW FITC-dextran $(p=0.002)$. These results suggest that rotation in a cell spinpod increased the activity of megalin, the receptor known to be responsible uptake of albumin and dextran $[51,52]$.

\section{Cytokine release induced by myeloma free light chains}

To further evaluate the increased activity of megalin, we exposed cell spinpod cultured renal cells to myeloma free light chains, which are also taken up by megalin [53]. Light chains from two donors were used - light chain B that showed a high degree of renal cell toxicity in vitro, under static conditions, and light chain $C$ that was only 
minimally toxic. Both light chains induced significant increased release of NGAL, IL-6, TNF- $\alpha$, and MCP-1 and light chain C induced significant release of IL-8 and GM-CSF in both static and rotating cell spinpods (data not shown). Fluid shear stress alone increased the quantity of IL-6 and GM-CSF (Figure 6, p=.003 and 0.006, respectively) in the media controls. The two light chains differed in their effects under fluid shear stress (Figure 6). Renal cells in rotating cell spinpods released significantly more GM-CSF $(p=0.004)$ in the presence of light chain $C$, and more IL- 6 in the presence of light chain $B(p=0.002)$ as compared to renal cells in static cell spinpods.

\section{Next generation sequencing}

Renal cells exposed to fluid shear stress in rotating suspension cultures upregulate distinct gene pathways compared to renal cells in static cultures. RNA-Seq analysis shows a difference in the identity and timing of gene expression responses of RPTEC/TERT1 renal cells in cell spinpods when they are static or rotated (Figure 7, Table I, Supplementary Table I). At 3 hours, the cells in static cell spinpods already display increases in genes involved in RNA gene expression and RNA polymerase biosynthesis, as well as those involved changes in cytokine signaling, apoptotic cell death, immune effector defense, and intracellular protein phosphorylation (data not shown). By 24 hours the cells in static cell spinpods manifest large changes in the categories of oxygen compound response, and apoptotic process regulation. At the same 24-hour time period, the rotating cells are showing changes in expression of genes involved in cell cycle regulation, apoptosis, and catabolic processes. Again, this is consistent with our flow cytometry and cytokine data, which, among other things suggests that cells in rotating cell spinpod culture are more metabolically active than those in static culture. By 72 hours the cells in static cell spinpods show changes in DNA metabolic response, oxidation reduction processes, oxidative stress response, cell cycle, and lipid metabolism. At the same 72-hour time point the rotating cells demonstrate changes in response to toxic compounds, cell death regulation, and vessel morphogenesis development. Supplemental Table I lists all of the names and statistics for all of the genes that differed significantly between rotating and static cell spinpod cultures of RPTEC/TERT1 at 3, 24, or 72 hours.

Notably, of all the common, well-characterized renal transporters, the only one to level change in the rotating cell spinpods was the breast cancer resistance protein (HGNC Gene Symbol ABC-G2, common symbol BCRP). BCRP was reduced at 3 hours in the static cultures (differential expression q-value 0.031), but this reduction was delayed in rotating cultures with differential expression q-values of 0.036 at 24 hours, and 0.02 at 72 hours respectively. There was no change at any time point in other drug transporters known to be expressed by PTC including Organic Anion Transporter 1 (OAT1), Organic Anion Transporter 3, (OAT-3) Organic Anion Transporter 4 (OAT-4), Urate Anion Exchanger 1, Organic Cation Transporter 2 (OCT-2), Multidrug and Toxin Extrusion Protein 1 (MDR-1, also known as MDR-1 and P-gp), Multidrug Resistance Associated Protein 2 (MDR-2), Multidrug Resistance Associated Protein 2 (MDRAP-1), or Multidrug Resistance Associated Protein 4 (MRAP-4). Similarly, the multiligand receptors megalin and cubilin responsible for the constitutive uptake of a vast variety of molecules [51] were present, but unchanged by rotation. 


\section{Discussion}

This study combines two major initiatives. First, it shows that injection molding and new membrane materials allow the production of inexpensive suspension culture devices, known as cell spinpods. Second, we present a use case demonstrating that cell spinpods provide a potent new tool to study renal physiology and pathophysiology, from cell and tissue constructs, through renal tumor culture to test interventions, and studies of nephrotoxicity (Table II).

Cell spinpods are a new generation of suspension culture devices in which careful design and selection of materials solve many of the problems encountered with previous generation suspension culture devices (Table II). Cell spinpods are inexpensive, easy to use, prevent bubble formation, maintain controlled levels of shear stress, and allow direct microscopy and fluorometric/ spectrophotometric analyses of cells still within the cell spinpod. A $3.5 \mathrm{~mL}$ vessel capacity was chosen as a 'Goldilockssize' to minimize the amount of media and cells (which are often expensive and limiting), yet provide enough sample for phenotyping, proteomics, and genomics. Our first technical innovation is the use of fluoropolymer for the breathable membranes which has better $\mathrm{O}_{2} / \mathrm{CO}_{2}$ exchange, while at the same time, much lower water vapor exchange, than the gas exchange membranes used in the previous generation rotating wall vessels. The low water vapor loss eliminates the formation of bubbles that disrupt laminar flow $[54,55]$. Our second innovation takes advantage of the improvement in direct current motors, allowing us to replace the expensive axle rotators and chronometers with inexpensive bottle rollers for a 10 - to 25 -fold cost reduction. Our third innovation is complete re-design of the filling ports to make them easier to use and automate. The ports are now made of self-sealing silicon rubber and placed axially, obviating the need for cumbersome en face 3-way taps or stopcocks (Table II).

The shear stress applied to cells during zero head space (i.e. no bubbles) suspension culture is determined by gravity, the radius of the particles squared, the difference in density between the cells and the media, and the viscosity of the media [1, $6,27,37,40-42,44]$. Changes in these parameters can be utilized to moderate the shear levels delivered during suspension culture. The dependence on gravity has made suspension culture a popular module for space flight studies and their ground-based simulations [6].

Of note, the speed of the rotation does not affect shear stress - it only affects the diameter of the annular circular path through which the cells move. Increasing the speed increases the diameter of the annulus, until at boundary conditions the cells collide with the outer walls of the rotating vessel $[1,44]$. However, so long as the annulus remains within the fluid space of the culture chamber, the shear stress remains constant despite small changes in rotation speed. This feature allows for a wide variety of cell sizes and cell spheroids to be cultured in cell spinpods. The stability and reproducibility of growth makes suspension culture a simple method for introducing physiologic levels of shear stress to cells in vitro. With the availability of inexpensive, 
easy-to-use cell spinpods, researchers now have a tool to affordably study shear stress using large numbers of replicates.

Precisely quantifying fluid mechanical forces experienced by cell suspension cultures at various operating conditions is critical to mimicking in vivo physiology and pathophysiology [43]. Specifically, the simple models of terminal velocity and maximum shear stress (above) can be generalized through the use of continuum mechanics in 3D. In doing so, precise predictions can be made regarding shear forces on cells, and how these flow forces vary throughout the volume of a rotating suspension culture [43].

The two phase modeling (TFM) simulation of conditions within the rotating cell spinpod further highlights the nonuniform distribution of particles throughout the crosssection of the cell chamber. The 3D suspension velocity field is not simply azimuthal (as in simple theoretical models), having some recirculation regions. Naturally, the highest stresses on the particle phase are encountered near the vessel wall (strongest shear) but rapidly decrease to a level of about 0.5 dynes $/ \mathrm{cm}^{2}$ in the annular region slightly inward from the wall, wherein the volume fraction of particles is highest $(\approx 30 \%)$.

We demonstrated in multiple ways that exposure to fluid shear stress in rotating cell spinpods maintains viability and enhances the function of renal cells. Renal cells in rotating cell spinpods: (a) were significantly more viable and less likely to be undergoing apoptosis, (b) released significantly lower quantities of the NGAL renal damage marker, (c) took up significantly greater quantities of albumin and dextran, and (d) increased the production of GM-CSF and IL-6. The doubling of renal proximal tubular cell albumin and dextran uptake induced by shear in rotating cell spinpods, shows that the cells remain physiologically responsive, and provides a simple model to investigate renal inflammation and fibrosis.

It has been more than 50 years since proximal tubular reabsorption of albumin by endocytosis was first demonstrated $[56,57]$ encompassing both nonspecific fluid-phase endocytosis and receptor-mediated endocytosis. In the kidney, proximal tubule receptor-mediated endocytosis is quantitatively extremely dominant [51]. Several receptors for tubular uptake of albumin and dextran have been identified, including the multiligand receptors megalin and cubilin, responsible for the constitutive uptake of a vast variety of molecules [51].

Increased albumin and dextran uptake is induced by shear in in a variety of renal cell models from HK-2, to rat and human primary proximal tubular cells, LLC-PK1 and conditionally immortalized human proximal tubular cells. [7, 8, 11, 12, 32]. The increase in albumin and dextran uptake is associated with greater megalin and cubilin expression [10]. To further validate the increased megalin functionality of renal cells exposed to fluid shear stress in rotating cell spinpods, we exposed the cells to myeloma light chains, which are also taken up by megalin [53]. Myeloma light chains induce an assortment of renal injuries with deposition in the glomerulus with glomerulonephritis, megalin mediated proximal tubular uptake, including induction of Fanconi system, as well as interstitial nephritis, and distal tubule cast nephropathy $[58,59]$. Renal cells in 
rotating cell spinpods released significantly more GM-CSF in the presence of light chains from one donor, where as they release significantly more IL-6 in the presence of light chains from the other donor. GM-CSF and IL-6 are associated with increased inflammation in the kidney and their lowered production in rotating cell spinpods suggests that physiologic levels of flow shear stress improve the health of proximal tubule cells. Renal cells produce IL-6 [60] and blocking IL-6 signaling reduces renal fibrosis in mice [61]. Renal cells produce GM-CSF when dissociated into cultures, but less so in vivo or when cellular density or substratum in the culture more closely approximate the in vivo environment [62]. The reduced production of GM-CSF by RPTEC/TERT1 in rotating cell spinpods suggests that this physiologic shear stress environment may be a better approximation of the milieu that PCT experience in vivo.

The gene expression analysis of renal proximal tubular cells in suspension culture has some predictable elements. Multiple heat shock proteins were amongst the largest gene expression changes, which is not surprising given their responsiveness to a wide variety of stressors. Similarly, several of the Cytoscape/ClueGo gene expression categories correlate with our functional studies which demonstrate changes in cell cycle, cellular stress, oxidation reduction process, and extracellular stimuli. Even more telling may be the gene expression which did not change. Cubilin is the classic example: the protein is so stable that there is scant RNA signal, to the point that investigators had to resort to embryonic tissue to find enough RNA signal to clone it [52]. Similarly, it is no surprise that expression changes in individual genes observed by other groups are absent in our analysis due to differences in cell type, method, timing, and intensity of shear stress application, and choice of renal proximal tubular cell homolog [2, 20]. Importantly for drug sensitivity studies, all the drug transporting channels were preserved, except for a small decrease in ABCG2.

Cell spinpods can be utilized in diverse configurations to answer disparate scientific questions [6, 63] (Table II). First, they are amenable to the culture of mammalian cells, insect cells, and microorganisms from bacteria to fungi and viruses. Second if anaerobic cultures are desired it is facile to replace the breathable membranes with gas impermeable membranes. Next, cell spinpod allow for studies of biofilm by replacing one breathable side membrane with a suitable growth matrix. In the same configuration, only partially filled cell spinpods can function as a roller bottle, with cells exposed to alternating fluid and air environments during rotation.

One area ripe for the application of cell spinpod culture is liver and kidney toxicity- each representing major obstacles for safe drug development [2, 20]. There are well-established, FDA-approved, high throughput screens for hepatotoxicity, but none for nephrotoxicity $[64,65]$. Modeling the full anatomical and functional complexity of a kidney is not a cost-effective approach for high throughput screening. Proximal tubule cells are a logical selection for in vitro screening as they take up and metabolize the majority of renally-filtered drugs and are the most frequent renal cell to show the toxic effects of drugs. Shear stress can maintain the differentiation of this key cellular target in vitro. Proximal tubule kidney cells cultured in suspension culture display differentiated features, such as expression of megalin, cubilin, and microvilli not seen in 
cells in static 2-D cultures $[5,10,30,66]$. We hypothesize that renal cells in cell spinpods will be a sensitive and informative model for evaluating nephrotoxicity [6].

The physiological and genomic studies presented here document the responses of renal cells to suspension culture. Our preliminary analysis of the global transcriptome and a focused panel of expressed proteins provides a reference against which experimental perturbations can be compared. The maintenance of all the major drug transport systems, is evidence that this prototype cell spinpod model is a suitable, scalable platform for drug toxicity testing. 
Table I. GSEA processes in RPTEC/TERT1 that are upregulated in rotating and static cell spinpods after 3,24 , and 72 hours compared to time zero.

\section{STATIC CELL SPINPODS}

3 hrs. vs 0 hrs.

- MA gene expression

- MA polymerase biosynthetic

- Developmental growth

- Intracell. protein phosphorylation

- Negative signaling stimulus

- Binding factor activity

- Response nitrogen compound

- Immune effector defense

- Negative regulation transport

- Response cytokine signaling

- Cell population proliferation

- Cell death apoptosis

- Cell differentiation developmental

- Blood morphogenesis devel.

- Component movement locomotion

- Animal organ morphogenesis

- Homeostasis cellular chemical

24 hrs. vs 0 hrs.

- Response oxygen compound

- Apoptotic process regulation

72 hrs. vs 0 hrs.

- Oxidation reduction process

- Response oxidative stress

- Lipid metabolic process

- Response DNA metabolic

- Negative cell cycle

\section{ROTATING CELL SPINPODS}

$3 \mathrm{hrs}$. vs $0 \mathrm{hrs}$.

- Cell motility regulation

- Formation involved morphogenesis

- Intracellular signal regulation

- Immune system activation

- Inflammatory response defense

- Response cytokine signaling

- Cellular response nitrogen

- Cell death apoptotic
24 hrs. vs 0 hrs.

- Catabolic macromolecule process

- Homeostasis cellular chemical

- Small molecule metabolic

- Molecular function negative

- Cellular response compound

- Molecular function negative

- Regulation cell cycle

- Positive polymerase

- Neuron death apoptotic

- Regulation cellular stress

72 hrs. vs 0 hrs.

- Death regulation cell

- Response wounding

- Vessel morphogenesis devel.

- Extracellular stimulus external

- Response toxic compound

- Reduction process metabolic

- Negative regulation signaling 
Table II. Advantages and uses of the cell spinpod form of rotational cell culture

- Orders of magnitude less expensive than current commercially available options

- Use small quantities of (often expensive) reagents and cells

- Occupy less space in laboratory incubators

- Are facile to fill and harvest

- Can be easily re-fed multiple times with minimal disruption in rotation

- Reagents can be added for analysis in situ

- Optically clear membranes allow inspection by microscopy in situ, including fluorescence microscopy

- Half-filled cell spinpods can serve as miniature roller bottles

- Adaptable to aerobic, anaerobic, and biofilm applications.

- Amenable to automated and robotic applications 


\section{Data availability}

All sequencing data is available through NASA GeneLab repository. 


\section{References}

1. Hammond, T.G. and J.M. Hammond, Optimized suspension culture: the rotatingwall vessel. American Journal Physiology Renal Physiology, 2001. 281(1): p. F12-25.

2. Birdsall, H.H. and T.G. Hammond, Role of Shear Stress on Renal Proximal Tubular Cells for Nephrotoxicity Assays. J Toxicol, 2021. 2021: p. 6643324.

3. Essig, M., F. Terzi, M. Burtin, and G. Friedlander, Mechanical strains induced by tubular flow affect the phenotype of proximal tubular cells. Am J Physiol Renal Physiol, 2001. 281(4): p. F751-62.

4. Guo, P., A.M. Weinstein, and S. Weinbaum, A hydrodynamic mechanosensory hypothesis for brush border microvilli. Am J Physiol Renal Physiol, 2000. 279(4): p. F698-712.

5. Cowger, N.L., E. Benes, P.L. Allen, and T.G. Hammond, Expression of renal cell protein markers is dependent on initial mechanical culture conditions. J Appl Physiol, 2002. 92(2): p. 691-700.

6. Hammond, T., P. Allen, and H. Birdsall, Is There a Space-Based Technology Solution to Problems with Preclinical Drug Toxicity Testing? Pharm Res, 2016. 33(7): p. 1545-51.

7. Ferrell, N., K.B. Ricci, J. Groszek, J.T. Marmerstein, and W.H. Fissell, Albumin handling by renal tubular epithelial cells in a microfluidic bioreactor. Biotechnol Bioeng, 2012. 109(3): p. 797-803.

8. Jang, K.J., A.P. Mehr, G.A. Hamilton, L.A. McPartlin, S. Chung, K.Y. Suh, and D.E. Ingber, Human kidney proximal tubule-on-a-chip for drug transport and nephrotoxicity assessment. Integr Biol (Camb), 2013. 5(9): p. 1119-29.

9. Jayagopal, A., P.R. Brakeman, P. Soler, N. Ferrell, W. Fissell, D.L. Kroetz, and S. Roy, Apical Shear Stress Enhanced Organic Cation Transport in Human OCT2/MATE1-Transfected Madin-Darby Canine Kidney Cells Involves Ciliary Sensing. J Pharmacol Exp Ther, 2019. 369(3): p. 523-530.

10. Kaysen, J.H., W.C. Campbell, R.R. Majewski, F.O. Goda, G.L. Navar, F.C. Lewis, T.J. Goodwin, and T.G. Hammond, Select de novo gene and protein expression during renal epithelial cell culture in rotating wall vessels is shear stress dependent. J Membr Biol, 1999. 168(1): p. 77-89.

11. Raghavan, V., Y. Rbaibi, N.M. Pastor-Soler, M.D. Carattino, and O.A. Weisz, Shear stress-dependent regulation of apical endocytosis in renal proximal tubule cells mediated by primary cilia. Proc Natl Acad Sci U S A, 2014. 111(23): $p$. 8506-11.

12. Xu, Y., S. Qin, Y. Niu, T. Gong, Z. Zhang, and Y. Fu, Effect of fluid shear stress on the internalization of kidney-targeted delivery systems in renal tubular epithelial cells. Acta Pharm Sin B, 2020. 10(4): p. 680-692.

13. Ferrell, N., J. Cheng, S. Miao, S. Roy, and W.H. Fissell, Orbital Shear Stress Regulates Differentiation and Barrier Function of Primary Renal Tubular Epithelial Cells. ASAIO J, 2018. 64(6): p. 766-772.

14. Bhat, V.D., P.A. Windridge, R.S. Cherry, and L.J. Mandel, Fluctuating shear stress effects on stress fiber architecture and energy metabolism of cultured renal cells. Biotechnol Prog, 1995. 11(5): p. 596-600. 
15. Cattaneo, I., L. Condorelli, A.R. Terrinoni, L. Antiga, F. Sangalli, and A. Remuzzi, Shear stress reverses dome formation in confluent renal tubular cells. Cell Physiol Biochem, 2011. 28(4): p. 673-82.

16. Duan, Y., N. Gotoh, Q. Yan, Z. Du, A.M. Weinstein, T. Wang, and S. Weinbaum, Shear-induced reorganization of renal proximal tubule cell actin cytoskeleton and apical junctional complexes. Proc Natl Acad Sci U S A, 2008. 105(32): p. 1141823.

17. Essig, M. and G. Friedlander, Tubular shear stress and phenotype of renal proximal tubular cells. J Am Soc Nephrol, 2003. 14 Suppl 1: p. S33-5.

18. Essig, M. and G. Friedlander, Shear-stress-responsive signal transduction mechanisms in renal proximal tubule cells. Curr Opin Nephrol Hypertens, 2003. 12(1): p. 31-4.

19. Maggiorani, D., R. Dissard, M. Belloy, J.S. Saulnier-Blache, A. Casemayou, L. Ducasse, S. Gres, J. Belliere, C. Caubet, J.L. Bascands, J.P. Schanstra, and B. Buffin-Meyer, Shear Stress-Induced Alteration of Epithelial Organization in Human Renal Tubular Cells. PLoS One, 2015. 10(7): p. e0131416.

20. Hammond, T.G. and H.H. Birdsall Hepatocyte CYP2B6 can be expressed in cell culture systems by exerting physiological levels of shear: implications for ADME testing. A review. J Toxicology, 2017. 1907952 DOI: 10.1155/2017/1907952.

21. Oo, Z.Y., R. Deng, M. Hu, M. Ni, K. Kandasamy, M.S. bin Ibrahim, J.Y. Ying, and D. Zink, The performance of primary human renal cells in hollow fiber bioreactors for bioartificial kidneys. Biomaterials, 2011. 32(34): p. 8806-15.

22. Aoki, S., T. Takezawa, H. Sugihara, and S. Toda, Progress in cell culture systems for pathological research. Pathol Int, 2016. 66(10): p. 554-562.

23. Wang, S., S. Godfrey, J. Ravikrishnan, H. Lin, J. Vogel, and J. Coffman, Shear contributions to cell culture performance and product recovery in ATF and TFF perfusion systems. J Biotechnol, 2017. 246: p. 52-60.

24. Kunnen, S.J., T.B. Malas, C.M. Semeins, A.D. Bakker, and D.J.M. Peters, Comprehensive transcriptome analysis of fluid shear stress altered gene expression in renal epithelial cells. J Cell Physiol, 2018. 233(4): p. 3615-3628.

25. Brown, L.A., L.M. Arterburn, A.P. Miller, N.L. Cowger, S.M. Hartley, A. Andrews, P.M. Silber, and A.P. Li, Maintenance of liver functions in rat hepatocytes cultured as spheroids in a rotating wall vessel. In Vitro Cell Dev Biol Anim, 2003. 39(1-2): p. 13-20.

26. Massai, D., G. Isu, D. Madeddu, G. Cerino, A. Falco, C. Frati, D. Gallo, M.A. Deriu, G. Falvo D'Urso Labate, F. Quaini, A. Audenino, and U. Morbiducci, $A$ Versatile Bioreactor for Dynamic Suspension Cell Culture. Application to the Culture of Cancer Cell Spheroids. PLoS One, 2016. 11(5): p. e0154610.

27. Klaus, D.M., Clinostats and bioreactors. Gravitational and Space Biology Bulletin, 2001. 14(2): p. 55-64.

28. Klaus, D.M., M.R. Benoit, E.S. Nelson, and T.G. Hammond, Extracellular mass transport considerations for space flight research concerning suspended and adherent in vitro cell cultures. Journal Gravitational Physiology, 2004. 11(1): p. 17-27.

29. Wieser, M., G. Stadler, P. Jennings, B. Streubel, W. Pfaller, P. Ambros, C. Riedl, H. Katinger, J. Grillari, and R. Grillari-Voglauer, hTERT alone immortalizes 
epithelial cells of renal proximal tubules without changing their functional characteristics. Am J Physiol Renal Physiol, 2008. 295(5): p. F1365-75.

30. Hammond, T.G., P.L. Allen, and H.H. Birdsall Gene pathways analysis of the effects of suspension culture on primary human renal proximal tubular cells. Microgravity Science and Technology, Online First, 2018. DOI: 10.1007/s12217018-9658-X.

31. Hammond, T.G. and P.L. Allen, The Bonn Criteria: Minimal experimental parameter reporting for clinostat and random positioning machine experiments. Microgravity Science and Technology, 2011. 23(2): p. 271-275.

32. Vriend, J., J.G.P. Peters, T.T.G. Nieskens, R. Skovronova, N. Blaimschein, M. Schmidts, R. Roepman, T.J.J. Schirris, F.G.M. Russel, R. Masereeuw, and M.J. Wilmer, Flow stimulates drug transport in a human kidney proximal tubule-on-achip independent of primary cilia. Biochim Biophys Acta Gen Subj, 2020. 1864(1): p. 129433.

33. Subramanian, A., P. Tamayo, V.K. Mootha, S. Mukherjee, B.L. Ebert, M.A. Gillette, A. Paulovich, S.L. Pomeroy, T.R. Golub, E.S. Lander, and J.P. Mesirov, Gene set enrichment analysis: a knowledge-based approach for interpreting genome-wide expression profiles. Proc Natl Acad Sci U S A, 2005. 102(43): p. 15545-50.

34. Shannon, P., A. Markiel, O. Ozier, N.S. Baliga, J.T. Wang, D. Ramage, N. Amin, B. Schwikowski, and T. Ideker, Cytoscape: a software environment for integrated models of biomolecular interaction networks. Genome Res, 2003. 13(11): p. 2498-504.

35. Bell, G.W. and F. Lewitter, Visualizing networks. Methods Enzymol, 2006. 411: p. 408-21.

36. Upadhyay, R., W.Z. Ying, Z. Nasrin, H. Safah, E.A. Jaimes, W. Feng, P.W. Sanders, and V. Batuman, Free light chains injure proximal tubule cells through the STAT1/HMGB1/TLR axis. JCI Insight, 2020. 5(14).

37. Schwarz, R.P., T.J. Goodwin, and D.A. Wolf, Cell culture for three-dimensional modeling in rotating-wall vessels: an application of simulated microgravity. $\mathrm{J}$ Tissue Cult Methods, 1992. 14(2): p. 51-7.

38. Todd, P., Physical effects at the cellular level under altered gravity conditions. Adv Space Res, 1992. 12(1): p. 43-9.

39. Klaus, D.M., P. Todd, and A. Schatz, Functional weightlessness during clinorotation of cell suspensions. Advances in Space Research, 1998. 21(8-9): $p$. 1315-8.

40. Niiya, T., M. Murakami, T. Aoki, N. Murai, Y. Shimizu, and M. Kusano, Immediate increase of portal pressure, reflecting sinusoidal shear stress, induced liver regeneration after partial hepatectomy. J Hepatobiliary Pancreat Surg, 1999. 6(3): p. 275-80.

41. Dash, A., M.B. Simmers, T.G. Deering, D.J. Berry, R.E. Feaver, N.E. Hastings, T.L. Pruett, E.L. LeCluyse, B.R. Blackman, and B.R. Wamhoff, Hemodynamic flow improves rat hepatocyte morphology, function, and metabolic activity in vitro. Am J Physiol Cell Physiol, 2013. 304(11): p. C1053-63.

42. Choi, K., W.P. Pfund, M.E. Andersen, R.S. Thomas, H.J. Clewell, and E.L. LeCluyse, Development of 3D dynamic flow model of human liver and its 
application to prediction of metabolic clearance of 7-ethoxycoumarin. Tissue Eng Part C Methods, 2014. 20(8): p. 641-51.

43. Municchi, F., P.P. Nagrani, and I.C. Christov, A two-fluid model for numerical simulation of shear-dominated suspension flows. International Journal of Multiphase Flow 2019. 120: p. 103079.

44. Chao, T.C. and D.B. Das, Numerical simulation of coupled cell motion and nutrient transport in NASA's rotating bioreactor. Chemical Engineering Journal, 2015. 259: p. 961-971.

45. Weller, H.G., G. Tabor, C. Fureby, and H. Jasak, A tensorial approach to computational continuum mechanics using object-oriented techniques. Comput. Phys., 1998. 12: p. 620-631.

46. Astashkina, A.I., B.K. Mann, G.D. Prestwich, and D.W. Grainger, A 3-D organoid kidney culture model engineered for high-throughput nephrotoxicity assays. Biomaterials, 2012. 33(18): p. 4700-11.

47. Astashkina, A.I., B.K. Mann, G.D. Prestwich, and D.W. Grainger, Comparing predictive drug nephrotoxicity biomarkers in kidney 3-D primary organoid culture and immortalized cell lines. Biomaterials, 2012. 33(18): p. 4712-21.

48. Srisawat, N., X. Wen, M. Lee, L. Kong, M. Elder, M. Carter, M. Unruh, K. Finkel, A. Vijayan, M. Ramkumar, E. Paganini, K. Singbartl, P.M. Palevsky, and J.A. Kellum, Urinary biomarkers and renal recovery in critically ill patients with renal support. Clin J Am Soc Nephrol, 2011. 6(8): p. 1815-23.

49. Wilmer, M.J., C.P. Ng, H.L. Lanz, P. Vulto, L. Suter-Dick, and R. Masereeuw, Kidney-on-a-Chip Technology for Drug-Induced Nephrotoxicity Screening. Trends Biotechnol, 2016. 34(2): p. 156-70.

50. Diekjurgen, D. and D.W. Grainger, A murine ex vivo 3D kidney proximal tubule model predicts clinical drug-induced nephrotoxicity. Arch Toxicol, 2019. 93(5): p. 1349-1364.

51. Birn, H. and E.I. Christensen, Renal albumin absorption in physiology and pathology. Kidney Int, 2006. 69(3): p. 440-9.

52. Moestrup, S.K., R. Kozyraki, M. Kristiansen, J.H. Kaysen, H.H. Rasmussen, D. Brault, F. Pontillon, F.O. Goda, E.I. Christensen, T.G. Hammond, and P.J. Verroust, The intrinsic factor-vitamin B12 receptor and target of teratogenic antibodies is a megalin-binding peripheral membrane protein with homology to developmental proteins. J Biol Chem, 1998. 273(9): p. 5235-42.

53. Klassen, R.B., P.L. Allen, V. Batuman, K. Crenshaw, and T.G. Hammond, Light chains are a ligand for megalin. J Appl Physiol, 2005. 98(1): p. 257-63.

54. Phelan, M.A., P.I. Lelkes, and A. Swaroop, Mini and customized low-cost bioreactors for optimized high-throughput generation of tissue organoids. Stem Cell Investig, 2018. 5: p. 33.

55. Phelan, M.A., A.L. Gianforcaro, J.A. Gerstenhaber, and P.I. Lelkes, An Air Bubble-Isolating Rotating Wall Vessel Bioreactor for Improved Spheroid/Organoid Formation. Tissue Eng Part C Methods, 2019. 25(8): p. 479488.

56. Maunsbach, A.B., Albumin absorption by renal proximal tubule cells. Nature, 1966. 212(5061): p. 546-7. 
57. Park, C.H. and T. Maack, Albumin absorption and catabolism by isolated perfused proximal convoluted tubules of the rabbit. J Clin Invest, 1984. 73(3): p. 767-77.

58. Hutchison, C.A., V. Batuman, J. Behrens, F. Bridoux, C. Sirac, A. Dispenzieri, G.A. Herrera, H. Lachmann, P.W. Sanders, K. International, and G. Monoclonal Gammopathy Research, The pathogenesis and diagnosis of acute kidney injury in multiple myeloma. Nat Rev Nephrol, 2011. 8(1): p. 43-51.

59. Doshi, M., A. Lahoti, F.R. Danesh, V. Batuman, P.W. Sanders, and F. American Society of Nephrology Onco-Nephrology, Paraprotein-Related Kidney Disease: Kidney Injury from Paraproteins-What Determines the Site of Injury? Clin J Am Soc Nephrol, 2016. 11(12): p. 2288-2294.

60. Demirel, I., R. Vumma, C. Mohlin, L. Svensson, S. Save, and K. Persson, Nitric oxide activates IL-6 production and expression in human renal epithelial cells. Am J Nephrol, 2012. 36(6): p. 524-30.

61. Chen, W., H. Yuan, W. Cao, T. Wang, W. Chen, H. Yu, Y. Fu, B. Jiang, H. Zhou, $\mathrm{H}$. Guo, and $\mathrm{X}$. Zhao, Blocking interleukin-6 trans-signaling protects against renal fibrosis by suppressing STAT3 activation. Theranostics, 2019. 9(14): p. 39803991.

62. Stephens, N.D., S.L. Barton, A.Y. Smith, R.W. Paul, J.A. Neidhart, and J.K. Griffith, GM-CSF secretion in primary cultures of normal and cancerous human renal cells. Kidney Int, 1996. 50(3): p. 1044-50.

63. Grimm, D., M. Wehland, J. Pietsch, G. Aleshcheva, P. Wise, J. van Loon, C. Ulbrich, N.E. Magnusson, M. Infanger, and J. Bauer, Growing tissues in real and simulated microgravity: new methods for tissue engineering. Tissue Eng Part B Rev, 2014. 20(6): p. 555-66.

64. Chauvin, M.F., C. Bolon, A. Conjard, G. Martin, B. Ferrier, M. Martin, C. Michoudet, D. Durozard, M.C. Lareal, C. Gauthier, H. Simonnet, M. Elhamri, S. Dugelay, B. Joly, and G. Baverel, Advantages and limitations of the use of isolated kidney tubules in pharmacotoxicology. Cell Biol Toxicol, 1996. 12(4-6): p. 283-7.

65. Gandolfi, A.J. and K. Brendel, In vitro systems for nephrotoxicity studies. Toxicol In Vitro, 1990. 4(4-5): p. 337-45.

66. Hammond, T.G., F.C. Lewis, T.J. Goodwin, R.M. Linnehan, D.A. Wolf, K.P. Hire, W.C. Campbell, E. Benes, K.C. O'Reilly, R.K. Globus, and J.H. Kaysen, Gene expression in space. Nature Medicine, 1999. 5(4): p. 359. 


\section{Author Contributions}

TH managed the project, collaborated on study design, and performed all the flow cytometry. PA performed the cell cultures and managed all aspects of the Durham lab. MA SLA printed initial generations of prototype cell spinpods. AR completed the CADD design, matured the next generations of SLA-printed prototypes, and managed the production. $\mathrm{CN}, \mathrm{MB}$, and GG performed the next generation sequencing and GSEA analysis, as well as providing critical commentary on the manuscript. PN and IC set up, performed and validated two-fluid model full-fidelity simulations of suspension flow and stresses in the cell spinpods. HB performed some of the cell cultures, collaborated on study design and acted as the data warden, storing and verifying all data, and performed all the statistics in a blinded manner. VB and RU purified the free light chains. All authors agree to be accountable for the content of the work and all contributed prose and/or figures in the manuscript.

\section{Additional Information}

\section{Funding}

NASA Grant 80NSSC19K0706 under solicitation NNH18ZTT001N-EM1 to the Institute for Medical Research supported these studies.

\section{Acknowledgments}

This material is the result of work supported with resources and the use of facilities at the Durham Veterans Affairs Health Care System, Duke University School of Medicine, University of British Columbia - Vancouver, Purdue University, and Tulane University School of Medicine. Contents do not represent the views of the Department of Veterans Affairs or the United States of America. CN and GG are both supported as Tier 1 Canadian Research Chairs. The Institute for Medical Research managed the grant funds. PN and IC thank Dr. Federico Municchi for fruitful discussions on two-fluid modeling.

\section{Conflict of Interest}

Author MA owns the company Incept 3D. Author AR owns the company Rite Tech Industries Inc. Authors HB and TH own the company Cell Spinpods LLC. The remaining authors declare that the research was conducted in the absence of any commercial or financial relationships that could be construed as a potential conflict of interest. 


\section{Figure Legends}

Figure 1. Components of the cell spinpod. Components of the cell spinpod. Panels (a) and (b) are CAD renderings. The cell/media chamber, in lilac, is sandwiched between two breathable membranes that are sealed on two sides with silicone rubber O-rings and held in place with retaining caps (shown in red) with eight snap features on each. There are two surface-bonded silicon rubber needle ports (shown in turquoise) incorporated through the side walls of the cell chamber, for loading cells/media and for bleeding the air during loading. Panel c shows an actual empty cell spinpod and Panel $d$ shows three views of a cell spinpod filled with pink media.

Figure 2. Loading, spinning, monitoring, and harvesting cell spinpods. Panel (a): Cells and media are loaded into the cell spinpod, held in a 3D-printed loading dock (blue), with a needle in one port and an air bleed needle in the second self-sealing port. (See also Supplemental video 2). Panel (b): Cell Spinpods are spun on an ordinary laboratory bottle roller so that contents are maintained under laminar flow conditions. (See also Supplemental video 1). Panel (c): Cells can be monitored in situ still within the Cell Spinpod by microscopy through the optically-clear gas exchange membranes when placed in the microscopy holder (blue), which places the cell spinpod's cellular contents in the focal length of most inverted microscopes. Panel (d): Cells can be harvested by incising the membrane or through a needle inserted in the ports.

Figure 3. Simulations of the flow and stresses in the cell spinpod. Two fluid model simulations of particle distribution and shear stress in cell spinpod. The flow of a suspension of particles of $d_{p}=175 \mu$ m diameter, at an initially homogeneous volume fraction $\phi_{0}=0.2$, was placed in the cylindrical space between two co-centric disks. The suspending fluid was taken to be water at standard conditions. The outer cylinder was rotated at $\omega=17 \mathrm{rpm}$ until the suspension reached a steady state (about $500 \mathrm{~s}$ later). The suspension's spatial volume fraction distribution, in an axial cross-section (i.e., perpendicular to the z-axis of rotation out of the page) at steady state is shown by the filled contours in the background of panel (a). Panel (a) further shows the superimposed velocity vectors color coded by magnitude. Panel (b) shows the corresponding distribution of the magnitude of the particle stress tensor in the same plane.

Figure 4. Effect of rotation in cell spinpods on viability of renal cells. Effect of rotation in cell spinpods on viability of renal cells. RPTEC/TERT1 cells on Cytodex carrier beads were cultured in cell spinpods under rotating or static conditions. After 2-3 days, cells were trypsinized off the carrier beads, stained with propidium iodide $(\mathrm{PI})$ and FITC annexin V, and analyzed by flow cytometry, panel (a). Necrotic cells are in the upper left quadrant (P|Pos/Annexin ${ }^{\text {neg }}$ ), Late apoptotic cells in the upper right quadrant $\left(\mathrm{PI}^{\mathrm{pos}} / \mathrm{Annexin}^{\mathrm{pos}}\right)$, Early apoptotic cells are in the lower right quadrant $\left(\mathrm{P} \mathrm{I}^{\text {neg}} / \mathrm{Annexin}^{\mathrm{pos}}\right)$, and Live cells are negative in the lower left quadrant $\left(\mathrm{PI}^{\text {neg/Annexin }}{ }^{\text {neg }}\right)$. Panel $(\mathbf{b})$ shows the proportion of cells from rotating and static cell spinpods that are necrotic, in late apoptosis, in early apoptosis, or live. Panel (c) shows the relative number of cells recovered from rotating versus static cell spinpods. Error bars indicate \pm SEM of six 
replicates and significance is estimated by two-tailed Student's t-test. Results are representative of four experiments.

Figure 5. Effect of rotation in cell spinpods on uptake of albumin and dextran by renal cells. Effect of rotation in cell spinpods on uptake of albumin and dextran by renal cells. RPTEC/TERT1 cells on Cytodex carrier beads were cultured in cell spinpods under rotating conditions (red bars) or static conditions (blue hatched bars). After 48 hours, media was replaced with FITC albumin (400 microg $/ \mathrm{mL})$ in serumdepleted media containing 20 microgram $/ \mathrm{mL}$ BSA, with FITC-Dextran $(1 \mathrm{mg} / \mathrm{mL})$ in complete media, or complete media alone (containing $200 \mathrm{microgm} / \mathrm{mL}$ albumin). Cultures were continued under rotating or static conditions for an additional 24 hours after which the cells were trypsinized off the carrier beads and analyzed by flow cytometry. Data is presented as mean fluorescence and error bars are \pm SEM of six replicates. Significance was estimated by two-tailed t-test. Rotation resulted in a significant increase in the uptake of both FITC-dextran $(p=0.002)$ and FITC- albumin $(p=0.006)$.

Figure 6. Effect of rotation in cell spinpods on cytokine release from renal cells. RPTEC/iTERT cells on Cytodex carrier beads were cultured in cell spinpods under rotating conditions $(\square)$ or static conditions ( $\square$ ). After 48 hours, supernatants were harvested for assay of cytokines. Data is presented as quantity of GM-CSF, panel (a) and IL-6, panel (b) in pg/mL; error bars are \pm SEM of six replicates. Significance was estimated by two-tailed t-test. Rotation induced significantly greater quantities of GMCSF in the media control $(p=0.005)$ and after stimulation with light chain $C(p=0.004)$ and significantly greater quantities of IL- 6 in the media control $(p=0.03)$ and after stimulation with light chain $B(p=0.002)$.

Figure 7. GSEA Analysis of RPTEC/TERT1 in rotation versus static conditions. RPTEC/TERT1 were incubated in static and rotating cell spinpods for $0,3,24$, and 72 hours and the RNA was collected for gene set enrichment analysis. The figure shows the enrichment maps, visualized in Cytoscape, for 3, 24, and 72 hours in static or rotating cell spinpods compared to 0 hour cultures.

\section{Supplemental Data}

Table S1: The table lists the genes that significantly increased or decreased with rotation. FPKM (fragments per kilobase of exon model per million reads mapped) is a normalized estimation of gene expression based on RNA-seq data. q-values are the name given to the adjusted $p$-values found using an optimized FDR approach.

Video 1: Beads in rotating cell spinpod. The video shows the path of Cytodex beads, stained with blue dye in a cell spinpod that is initially at rest and then begins to spin as the bottle roller is accelerated in step-wise increments.

Video 2: Loading of cell spinpods. The video shows the loading process for cell spinpods using gravity feed. The media is introduced through an infusion set using an 
18-gauge needle. A 27-gauge needle in the upper port allows the evacuation of air as the cell spinpod fills. 


\section{Figures}
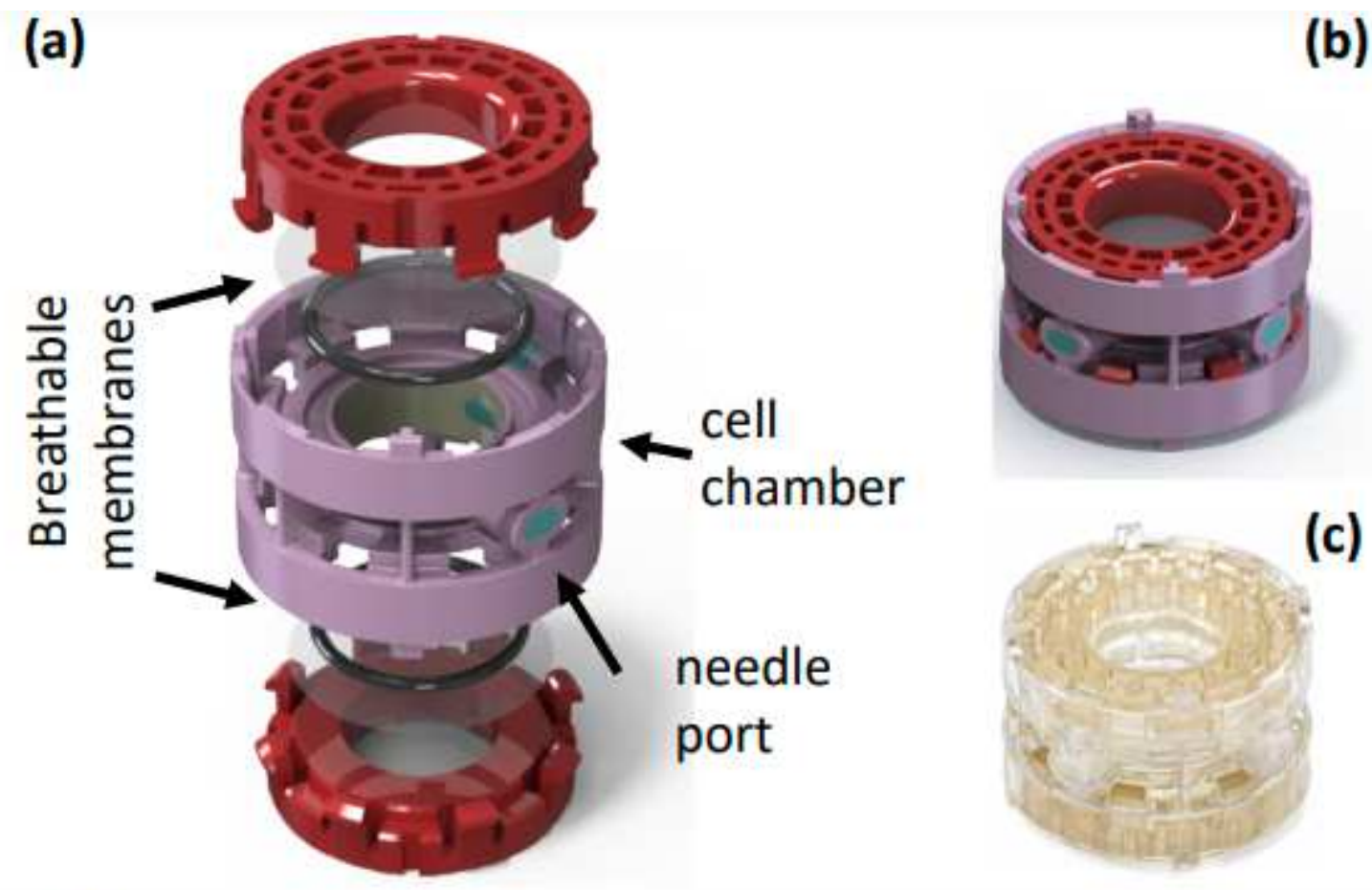

(c)
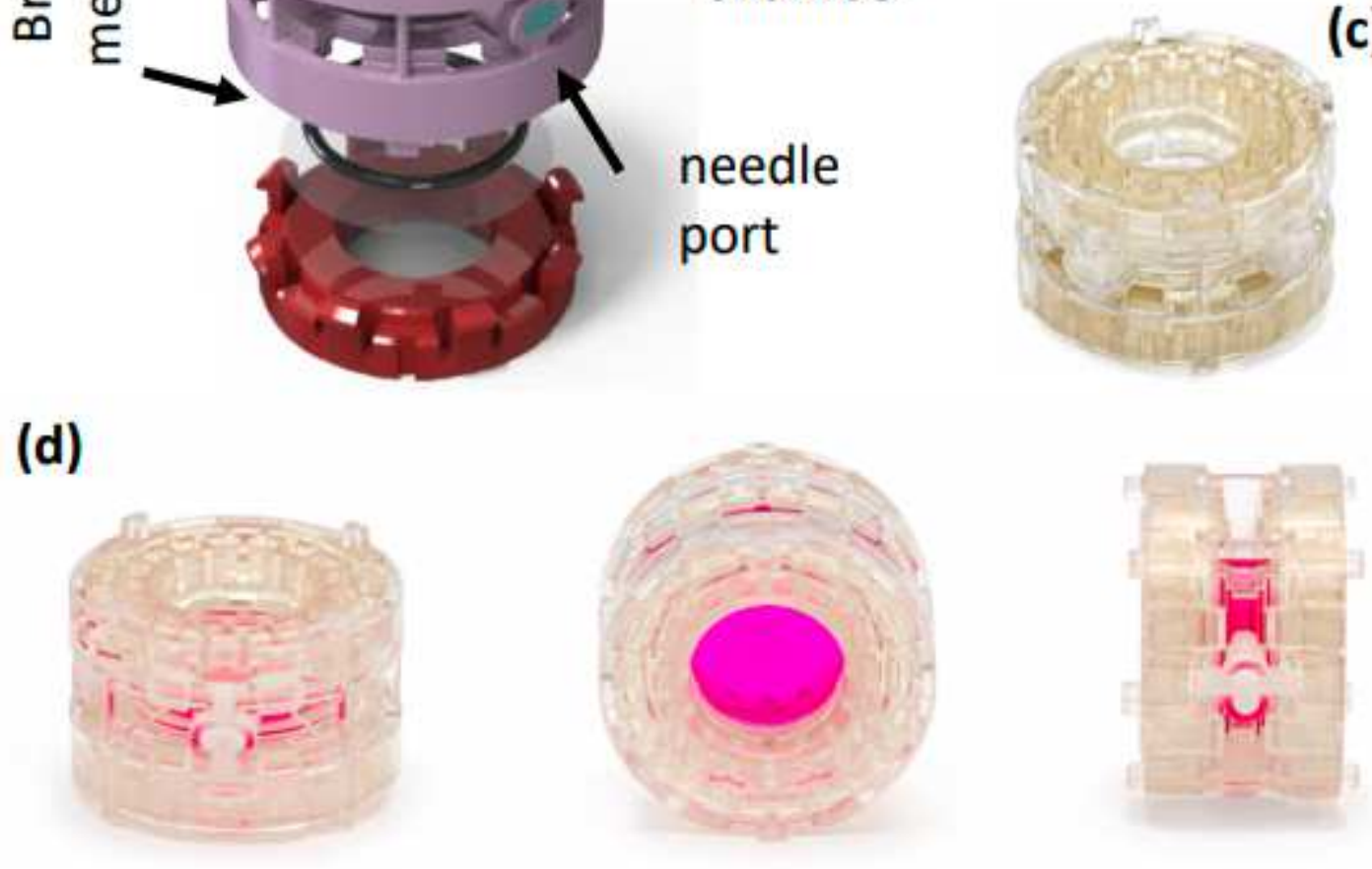

(b)

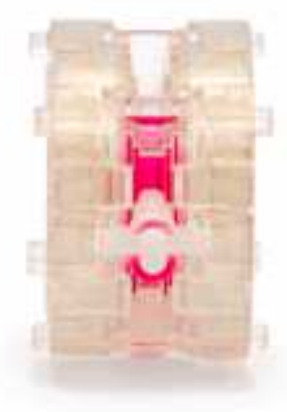

\section{Figure 1}

Components of the cell spinpod. Components of the cell spinpod. Panels (a) and (b) are CAD renderings. The cell/media chamber, in lilac, is sandwiched between two breathable membranes that are sealed on two sides with silicone rubber O-rings and held in place with retaining caps (shown in red) with eight snap features on each. There are two surface-bonded silicon rubber needle ports (shown in turquoise) incorporated through the side walls of the cell chamber, for loading cells/media and for bleeding the air during loading. Panel $c$ shows an actual empty cell spinpod and Panel $d$ shows three views of a cell spinpod filled with pink media. 


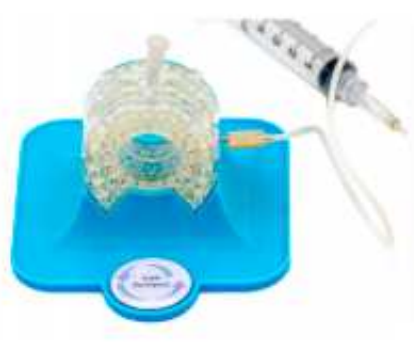

(a) Load

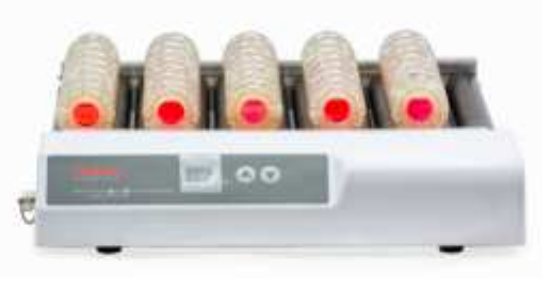

(b) Spin

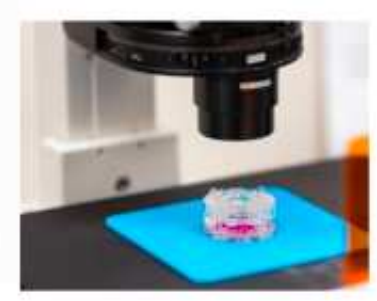

(c) Monitor

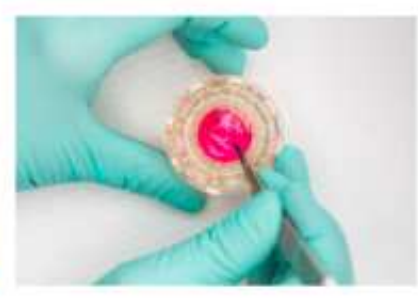

(d) Harvest

\section{Figure 2}

Loading, spinning, monitoring, and harvesting cell spinpods. Panel (a): Cells and media are loaded into the cell spinpod, held in a 3D-printed loading dock (blue), with a needle in one port and an air bleed needle in the second self-sealing port. (See also Supplemental video 2). Panel (b): Cell Spinpods are spun on an ordinary laboratory bottle roller so that contents are maintained under laminar flow conditions. (See also Supplemental video 1). Panel (c): Cells can be monitored in situ still within the Cell Spinpod by microscopy through the optically-clear gas exchange membranes when placed in the microscopy holder (blue), which places the cell spinpod's cellular contents in the focal length of most inverted microscopes. Panel (d): Cells can be harvested by incising the membrane or through a needle inserted in the ports. 
(a)
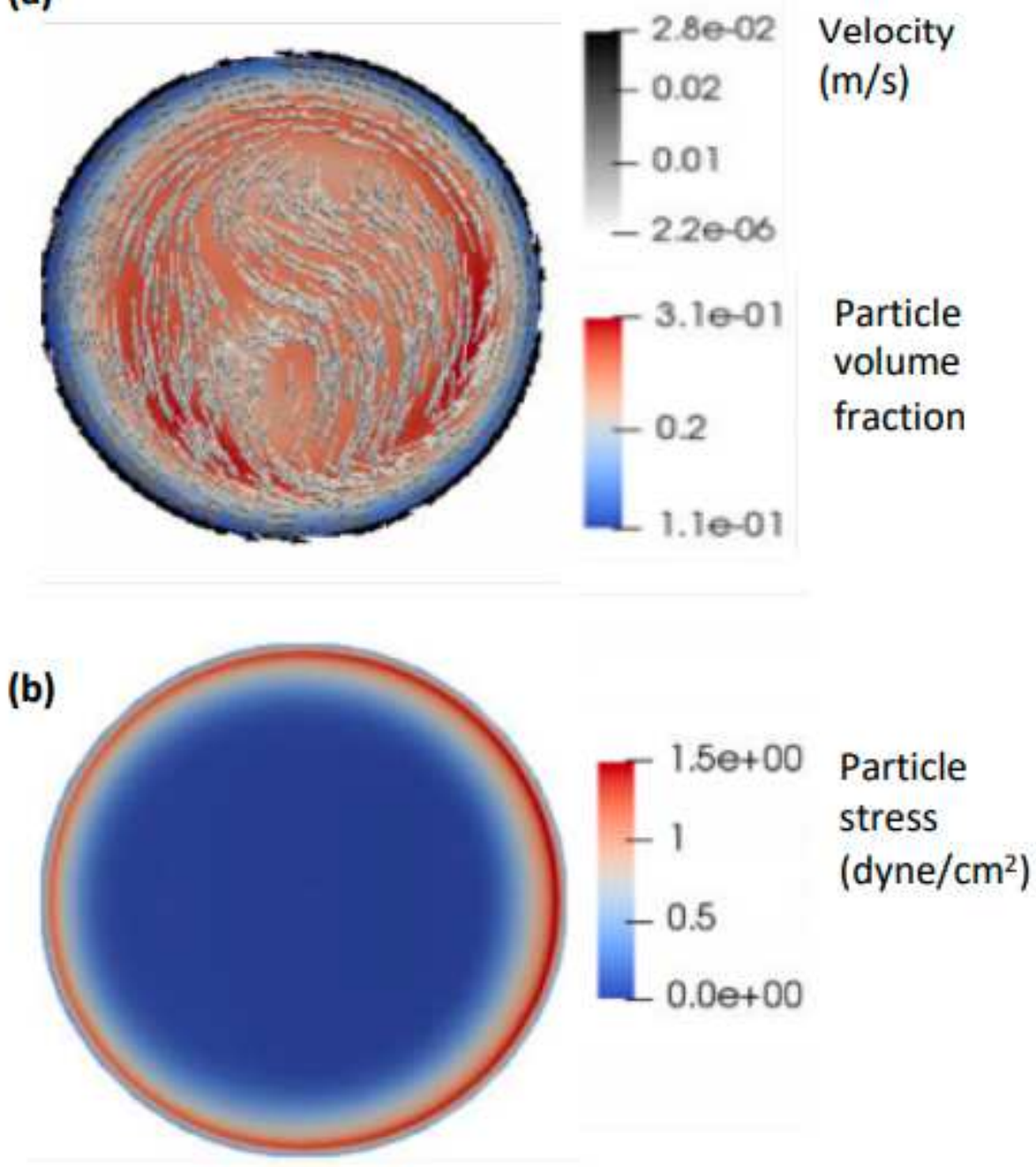

\section{Figure 3}

Simulations of the flow and stresses in the cell spinpod. Two fluid model simulations of particle distribution and shear stress in cell spinpod. The flow of a suspension of particles of $d A=175 \mu \mathrm{m}$ diameter, at an initially homogeneous volume fraction $\mathbb{Q G}=0.2$, was placed in the cylindrical space between two co-centric disks. The suspending fluid was taken to be water at standard conditions. The outer cylinder was rotated at $\omega=17 \mathrm{rpm}$ until the suspension reached a steady state (about $500 \mathrm{~s}$ later). The suspension's spatial volume fraction distribution, in an axial cross-section (i.e., perpendicular to the zaxis of rotation out of the page) at steady state is shown by the filled contours in the background of panel (a). Panel (a) further shows the superimposed velocity vectors color coded by magnitude. Panel (b) shows the corresponding distribution of the magnitude of the particle stress tensor in the same plane. 
(a)

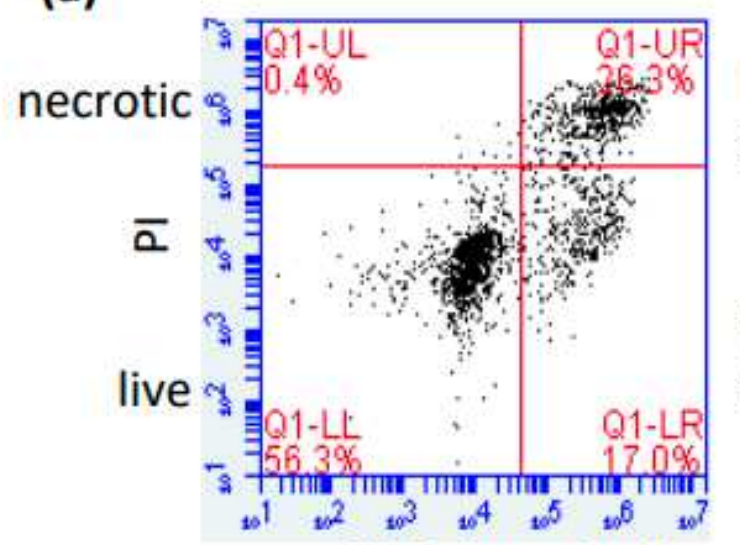

FITC-Annexin V (b) late
apoptotic early apoptotic necrotic

口late apoptotic

$\square$ early apoptotic

口live

Figure 4

Effect of rotation in cell spinpods on viability of renal cells. Effect of rotation in cell spinpods on viability of renal cells. RPTEC/TERT1 cells on Cytodex carrier beads were cultured in cell spinpods under rotating or static conditions. After 2-3 days, cells were trypsinized off the carrier beads, stained with propidium iodide (PI) and FITC annexin V, and analyzed by flow cytometry, panel (a). Necrotic cells are in the upper left quadrant (Plpos/Annexinneg), Late apoptotic cells in the upper right quadrant (Plpos/Annexinpos), Early apoptotic cells are in the lower right quadrant (PIneg/Annexinpos), and Live cells are negative in the lower left quadrant (PIneg/Annexinneg). Panel (b) shows the proportion of cells from rotating and static cell spinpods that are necrotic, in late apoptosis, in early apoptosis, or live. Panel (c) shows the relative number of cells recovered from rotating versus static cell spinpods. Error bars indicate + SEM of six 25 replicates and significance is estimated by two-tailed Student's t-test. Results are representative of four experiments. 


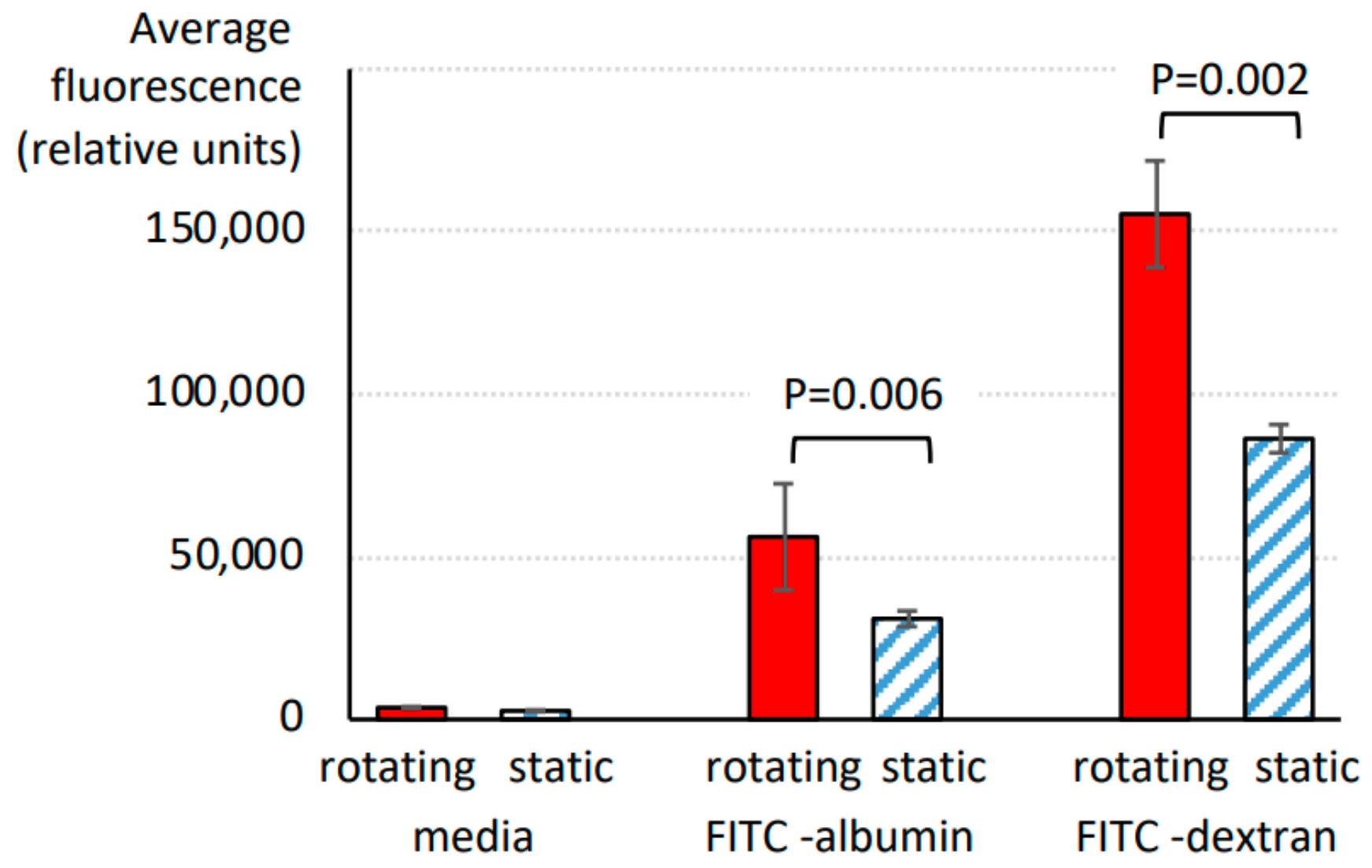

Figure 5

Effect of rotation in cell spinpods on uptake of albumin and dextran by renal cells. Effect of rotation in cell spinpods on uptake of albumin and dextran by renal cells. RPTEC/TERT1 cells on Cytodex carrier beads were cultured in cell spinpods under rotating conditions (red bars) or static conditions (blue hatched bars). After 48 hours, media was replaced with FITC albumin (400 microg/mL) in serum囚depleted media containing 20 microgram $/ \mathrm{mL} \mathrm{BSA}$, with FITC-Dextran $(1 \mathrm{mg} / \mathrm{mL})$ in complete media, or complete media alone (containing $200 \mathrm{microgm} / \mathrm{mL}$ albumin). Cultures were continued under rotating or static conditions for an additional 24 hours after which the cells were trypsinized off the carrier beads and analyzed by flow cytometry. Data is presented as mean fluorescence and error bars are + SEM of six replicates. Significance was estimated by two-tailed t-test. Rotation resulted in a significant increase in the uptake of both FITC-dextran $(p=0.002)$ and FITC- albumin $(p=0.006)$. 


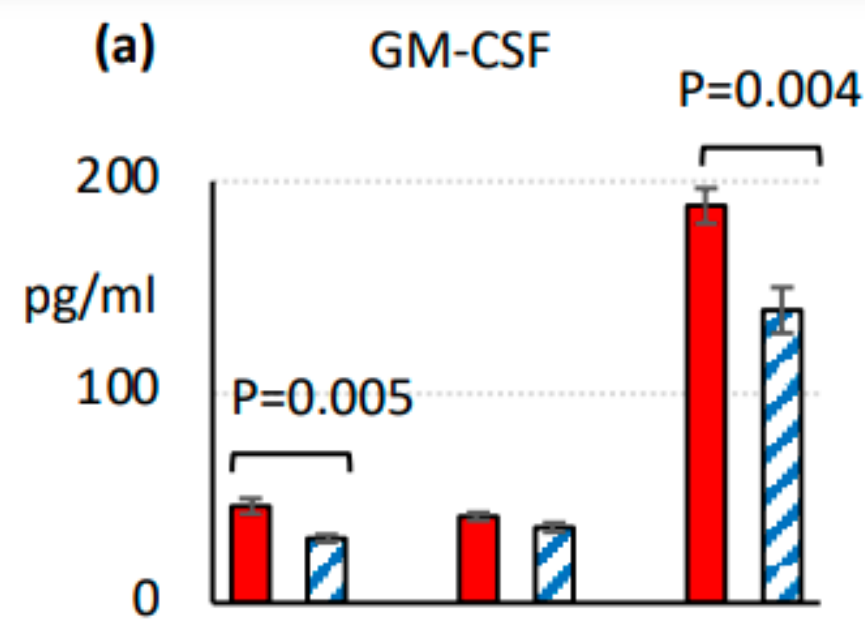

(b) $\quad$ IL-6

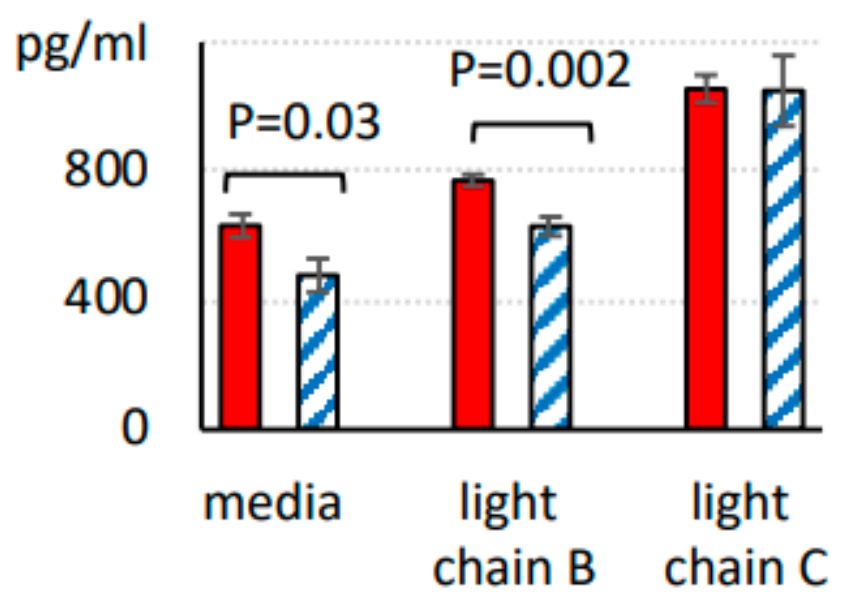

Figure 6

Please see the Manuscript PDF file for the complete figure caption 
24 hours

vs. 0 hours response oxygen compound apoptotic process regulation

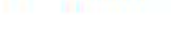

$=$ vs. 0 hours
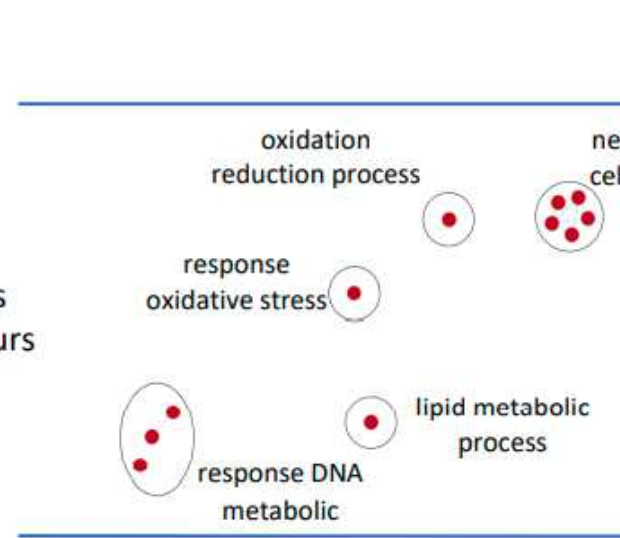

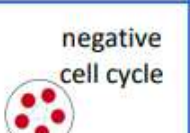

$\because$

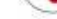

.

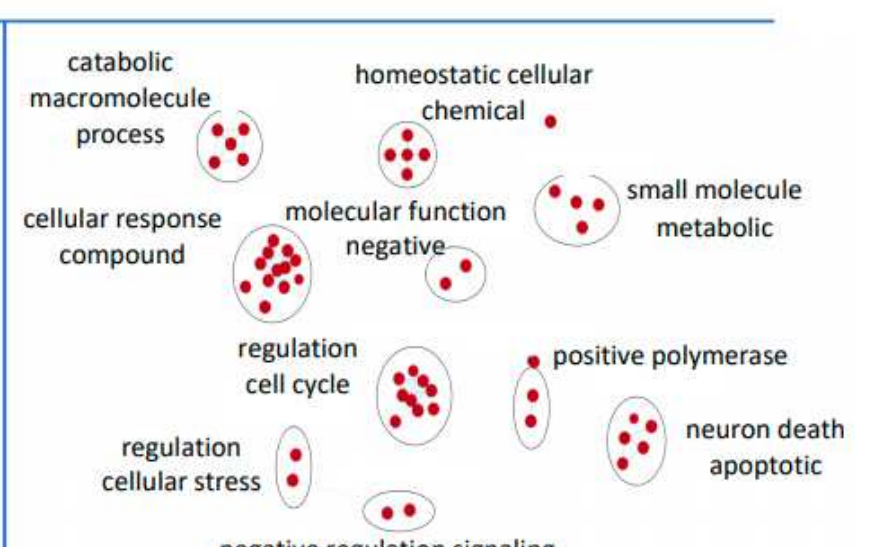

negative regulation signaling

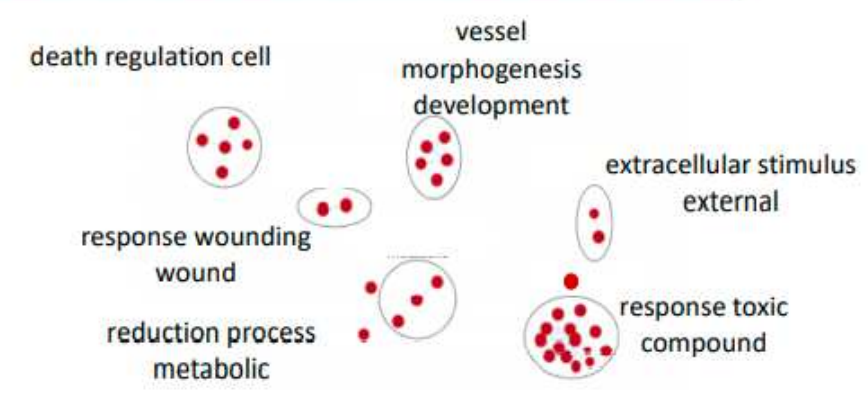

\title{
Figure 7
}

GSEA Analysis of RPTEC/TERT1 in rotation versus static conditions. RPTEC/TERT1 were incubated in static and rotating cell spinpods for $0,3,24$, and 72 hours and the RNA was collected for gene set enrichment analysis. The figure shows the enrichment maps, visualized in Cytoscape, for 3, 24, and 72 hours in static or rotating cell spinpods compared to 0 hour cultures.

\section{Supplementary Files}

This is a list of supplementary files associated with this preprint. Click to download.

- SUPPLEMENTALTablel.pdf

- Supplementalvideo1.mp4

- Supplementalvideo2.mp4 